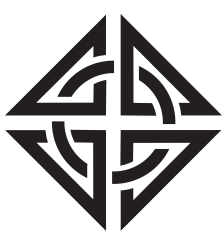

SCIENTIA
Sharif University of Technology

Scientia Iranica

Transactions C: Chemistry and Chemical Engineering

www.scientiairanica.com

\title{
Phenol removal from aqueous solution by adsorption process: Study of the nanoparticles performance prepared from aloe vera and mesquite (prosopis) leaves
}

\author{
M. Malakootian ${ }^{a}$, H.J. Mansoorian ${ }^{\mathrm{a}, \mathrm{b}, \mathrm{c}, *}$, M. Alizadeh ${ }^{\mathrm{d}}$ and A. Baghbanian $^{\mathrm{e}}$ \\ a. Environmental Health Engineering Research Center, Department of Environmental Health, Kerman University of Medical \\ Sciences, Kerman, Iran. \\ b. Department of Environmental Health Engineering, School of Public Health, Tehran, University of Medical Science, Tehran, Iran. \\ c. Young Researchers and Elite Clube, Hamedan Branch, Islamic Azad University, Hamedan, Iran. \\ d. Department of Environmental Health Engineering, School of Public Health, Zahedan University of Medical Sciences, Zahedan, \\ Iran. \\ e. Lecturer and Research Fellow in Health policy and Economics, Health Systems and Global Populations, Faculty of Health \\ Sciences, The University of Sydney, Sydney, Australia.
}

Received 3 December 2016; received in revised form 2 May 2017; accepted 11 September 2017

\author{
KEYWORDS \\ Agricultural solid \\ waste; \\ aloe vera; \\ mesquite; \\ Nanoparticle; \\ Phenol removal; \\ Adsorption isotherms; \\ Adsorption kinetics.
}

\begin{abstract}
This study was performed to measure the potential utilization of agro-waste to generate nanoparticles and evaluate its capability as a low-cost adsorbent for phenol removal. Adsorption studies for phenol removal using aloe vera and mesquite leaves nanoparticles were carried out under various experimental conditions including $\mathrm{pH}$, nanobioadsorbent dosage, phenol concentration, contact time, temperature, and ionic strength in a batch reactor. The adsorption kinetics were applied by pseudo-first order and pseudosecond order models and isotherm technique by Freundlich and Langmuir isotherms models. The results showed that the rate of phenol adsorption increases in both nano-bioadsorbents with an increase in $\mathrm{pH}$ up to 7 , adsorbent dosage up to $0.08 \mathrm{gL}^{-1}$, phenol initial concentration up to $32 \mathrm{mgL}^{-1}$, contact time up to $60 \mathrm{~min}$, and a raise in temperature. The adsorption data followed the Freundlich isotherm model. The kinetic studies indicated that the adsorption of phenol with nano-bioadsorbents was best described by the pseudo-second order kinetics. We found that the nanoparticles prepared from aloe vera and mesquite leaves had a high capability in adsorption of phenol, besides the point that they could be accessed at low cost. These agro-wastes can be used to remove phenol from aqueous environments. (C) 2017 Sharif University of Technology. All rights reserved.
\end{abstract}

\section{Introduction}

The presence of persistent toxic substances within environment is a major environmental problem. One

\footnotetext{
*. Corresponding author. Tel.: +983431325074; Fax: +983431325105

E-mail address: h.mansoorian@yahoo.com (H.J. Mansoorian)
}

doi: $10.24200 /$ sci. 2017.4524 of the classified pollutant compounds in environment is phenol due to its specific properties, such as toxicity, carcinogenicity, taste, and odor problems, in drinking water, causing adverse effects on human health and living organisms, according to reports of the Environmental Protection Agency of America (US EPA) [1,2]. Phenol or hydroxyl benzene $\left(\mathrm{C}_{6} \mathrm{H}_{6} \mathrm{O}\right)$ is one of the aromatic hydrocarbons and derivatives of benzene that has high solubility in water. Phenol solubility in water is 93-98 $\mathrm{gL}^{-1}$ (depending on the temperature between $20-25^{\circ} \mathrm{C}$ ) $[3,4]$. Phenol and its derivatives are 
aromatic compounds widely used in many industries such as petrochemical, paints, textiles, resins, plastics, and so forth. Hence, they are widely released into the environment as air pollutants and cause major problems even in low concentrations [5-7]. The threshold concentration of phenol in drinking water is recommended (to be) less than $1.0 \mu \mathrm{gL}^{-1}$ by both World Health Organization (WHO) and U.S.EPA regulations; they constantly request for lowering phenol content in wastewaters to less than $1 \mathrm{mgL}^{-1}[8,9]$. Eventually, due to their harmful effects, wastewaters containing phenol and other toxic compounds must be treated before being discharged into receiving water bodies. Several methods have been investigated for the removal and degradation of phenolic compounds from aqueous solutions. These include physicochemical treatment processes, chemical oxidation, biological degradation, and combined techniques [10-13]. Many of these processes have disadvantages such as the generation of dangerous by-products, low efficiency and applicability to limit concentrations of pollutants [9]. Among them, adsorption technique is one of the effective methods, quite popular in removing various pollutants due to its simplicity, high efficiency, easy handling, high selectivity, minimization of the production of chemical or biological sludge as well as the availability of a wide range of adsorbents [11,12]. A number of adsorbents have been used for phenol removal; for example, activated carbon, red mud, rubber seed coat, fly ash, organobentonite, surfactant-modified natural zeolite, and organomodified tirebolu bentonite. It is considered that adsorption of phenol by activated carbons is a well-known process, because it has a large surface area and results in high adsorption capacity $[8,12]$. However, high cost of production, reclamation, purification, and irreversible nature of adsorption reduce its usage as an adsorbent, particularly in developing and low-income countries. Therefore, these issues have led many scientists to work on cheap and locally available absorbents for substituting activated carbon to remove different biodegradability pollutants and organic chemicals, such as phenol. Hence, in recent years, special attention has been drawn to the use of industrial and agricultural wastes to remove toxic and dangerous pollutants from water and wastewater as potential adsorbents $[14,15]$. This is likely to be the first attempt to synthesize nanoparticles from aloe vera and mesquite leaves as new, available and low-cost materials for the removal of phenol. Unique properties of bioadsorbents provide new opportunities for the removal of pollutants with high efficiency and costeffective method. On the other hand, it is shown that nanoparticles efficiently have a promising adsorption related to the removal of various pollutants because of the high surface area, more active sites, and special properties $[11,15]$. Aloe vera or aloe barbadensis is an herbaceous plant with thick and fleshy leaves, mainly growing in tropical and subtropical dry zones. aloe vera belongs to the Liliaceae family and aloiede group. This plant contains anthraquinones derivatives such as aloin, barbaloin, isobarbaloin, and anthranol. Other important components of aloe vera consist of sugars (such as glucose, mannose, and cellulose) and enzymes (including oxidase, amylase and catalase, and folic acid), and minerals (such as calcium, sodium, magnesium, and zinc). This plant is mostly used in pharmaceuticals and cosmetic industries [16]. Prosopis plant is from Mimosaceae families which are common in many arid and semi-arid climates as trees and shrubs. It can grow in different countries including India, Pakistan, Nigeria, Ghana, Brazil, Peru, and South coast of Iran (Sistan and Baluchestan, Hormozgan, Bushehr, Khuzestan, and south of Fars). This plant is relatively considered a good source of crude protein, crude fat, crude fiber, ash, calcium, and phosphorus. Fuel and fencing, sand dune stabilization, stabilization of nitrogen in the soil, and forage source for livestock feeding can be cited as its applications. Prosopis genus covers 44 different species including four species of prosopis julifilora, prosopis farcta, prosopis cineraria, and prosopis koelziana found in Iran $[17,18]$. Prosopis cineraria leaves (because of its abundance in Sistan \& Baluchestan province) were used in this study as a nano-bioadsorbent. The objectives of this study are: (i) To determine the feasibility of developing a new and inexpensive alternative of nano-bioadsorbents based on agricultural wastes for the removal of phenols from aqueous solutions; (ii) To investigate the main effects of experimental parameters on the removal of phenols, such as pH, nano-bioadsorbent dosage, initial concentration, contact time, temperature, and ionic strength; and (iii) To study the adsorption capacity of the nano-bioadsorbents using the adsorption isotherm technique and kinetics of adsorption of phenol on the nano-bioadsorbents using different models.

\section{Materials and methods}

\subsection{Supply and preparation of adsorbent}

mesquite and aloe vera leaves were used as natural adsorbents. In fact, known as agricultural waste, it was prepared in Iranshahr city located in SistanBaluchistan Province. The preparation process of the desired nano-bioadsorbents was as follows. After collecting wastes, they were washed with distilled water several times to remove impurities. Then, leaves dried for 3 hours at $105^{\circ} \mathrm{C}$ in the oven. They were burned in the oven to be converted into ash at a temperature of $700^{\circ} \mathrm{C}$ for $1 \mathrm{~h}$. Then, it was milled by the Los Angeles abrasion to prepare the adsorbents in nanometer size and shed them to the mill (NARYA MPM-2* 250 model). Stearic acid equaling $3 \%$ of adsorbent weight 
was added to convert adsorbent particles to nanoscale. Steel balls were used in this study in a ratio of 1 to 7 (adsorbent weight to balls).

\subsection{Batch adsorption experiments}

The chemicals and reagents were applied to analytical grade and used without extra purification with an exception of deionized water, which was used as the solvent. All experiments were done by the use of double-distilled water. A stock phenol solution of $1000 \mathrm{mgL}^{-1}$ was prepared by dissolving $1.0 \mathrm{~g}$ of phenol obtained from Merck (Darmstadt, Germany) in $1 \mathrm{~L}$ of deionized water. The required concentration of phenol solutions was prepared by diluting the appropriate volumes of the stock solution. The $\mathrm{pH}$ of the solutions was adjusted by the addition of $0.1 \mathrm{M} \mathrm{HCl}$ or $0.1 \mathrm{M}$ $\mathrm{NaOH}$ solutions. A digital pH meter (DHP-500, SICO, UK) was used to measure $\mathrm{pH}$ values. Phenolspiked synthetic water samples were used to determine and measure the effective parameters as well as the adsorption capacity and percentage of phenol removed from aqueous solutions using nanoparticles from aloe vera leaf extract and mesquite bioadsorbents. Effective parameters include $\mathrm{pH}$, nano-bioadsorbent dosage, initial concentrations of phenol, contact time, reaction temperature, and ionic strength; their amounts are cited in Table 1. To examine the influence of ionic strength on phenol removal, $\mathrm{NaNO}_{3}, \mathrm{NaCl}, \mathrm{Na}_{2} \mathrm{SO}_{4}$, and $\mathrm{NaHCO}_{3}$ salts and various concentrations were individually added to water solutions. Batch adsorption experiments were carried out in $100 \mathrm{ml}$ sample flasks. To start each adsorption test of phenol, synthetic produced water samples with predetermined conditions were loaded into a $100 \mathrm{ml}$ polythene vial (Table 1). The sample vials were shaken on a rotary shaker (GFL 137 ) with 120 -rpm speed in order to appropriately mix the absorbent and adsorbate. The samples were then withdrawn at predetermined time intervals, and the mixture was filtered with the filter paper (Whatman No. $45 \mu \mathrm{m}$ ) with an aim of measuring the residual phenol concentration using a UV-vis spectrophotometer (Shimadzo-1700, Japan) at wavelength of $520 \mathrm{~nm}$ with Standard Methods [19]. The equilibrium adsorption capacity, $q_{e}\left(\mathrm{mgg}^{-1}\right)$, and the percentage removal were calculated using Eqs. (1) and (2), respectively:

$$
\begin{aligned}
q_{e} & =\frac{V}{M} \times\left(C_{0}-C_{e}\right), \\
E & =\frac{C_{0}-C_{e}}{C_{0}} \times 100,
\end{aligned}
$$

where $C_{0}$ is the initial concentration of phenol in solution $\left(\mathrm{mgL}^{-1}\right), C_{e}$ is the equilibrium concentration of phenol in aqueous solution $\left(\mathrm{mgL}^{-1}\right), V$ is the volume of solution (L), $M$ is the mass of adsorbent $(\mathrm{g}), q_{e}$ is the amount of absorbed phenol at equilibrium time $\left(\mathrm{mgg}^{-1}\right)$, and $E$ is the removal efficiency.

The adsorption isotherms were described by Langmuir and Freundlich isotherm models for understanding the adsorption mechanism. Adsorption kinetics were also applied by the pseudo-first-order and pseudo-second-order models for understanding the adsorption rates of phenol on the surfaces of nanobioadsorbents and determining the equilibrium times of adsorptions.

\section{Result and discussion}

\subsection{Morphology and determination of specific surface area, particle distribution, methylene blue, and iodine numbers of nano-bioadsorbent}

The morphologies of adsorbent as nanoparticles were obtained using a Field Emission Scanning Electron Microscope (FESEM, FEINova-Nano SEM-600, Netherlands), shown in Figure 1(a) and (b). Nanobioadsorbents surface area was determined according to Brunauer-Emmett-Teller Method (BET) using Tristar 3000 Micromeritics device (Micromeritics Instrument Corp., USA) [20,21]. The results of BET method showed that average surface areas of aloe vera and mesquite nanoparticles were 41.25 and $\mathrm{m}^{2} \mathrm{~g}^{-1}$ and $38.76 \mathrm{~m}^{2} \mathrm{~g}^{-1}$, respectively. Average particle size of the nano-bioadsorbent was $95 \mathrm{~nm}$ according to the Barret, Joyner, and Halenda method (BJH) through adsorption and desorption curves of nitrogen at 77 degrees Kelvin using Micromeritics Tristar 3000 device [20,22]. Two other important parameters used in indicating

\begin{tabular}{|c|c|c|}
\hline Number & Parameter & Value \\
\hline 1 & $\mathrm{pH}$ & $3,5,7,9,11$ \\
\hline 2 & Adsorbent dose & $0.01,0.02,0.04,0.08,0.1,0.3 \mathrm{gL}^{-1}$ \\
\hline 3 & Initial concentrations of phenol & $0.1,0.5,1,2,4,8,16,32,64 \mathrm{mgL}^{-1}$ \\
\hline 4 & Contact time & $10,20,30,40,50,60,70,90 \mathrm{~min}$ \\
\hline 5 & Temperature & $25,35,45,55^{\circ} \mathrm{C}$ \\
\hline 6 & $\mathrm{NaNO}_{3}, \mathrm{NaCl}, \mathrm{Na}_{2} \mathrm{SO}_{4}$, and $\mathrm{NaHCO}_{3}$ & $0.01,0.05,0.1,0.15,0.2,0.25 \mathrm{M}$ \\
\hline
\end{tabular}

Table 1. Evaluation of parameters and their range. 


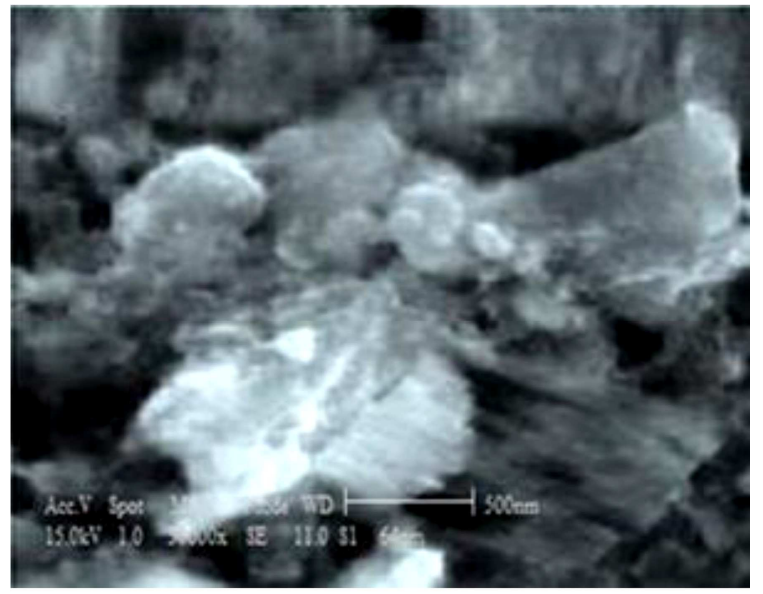

(a)

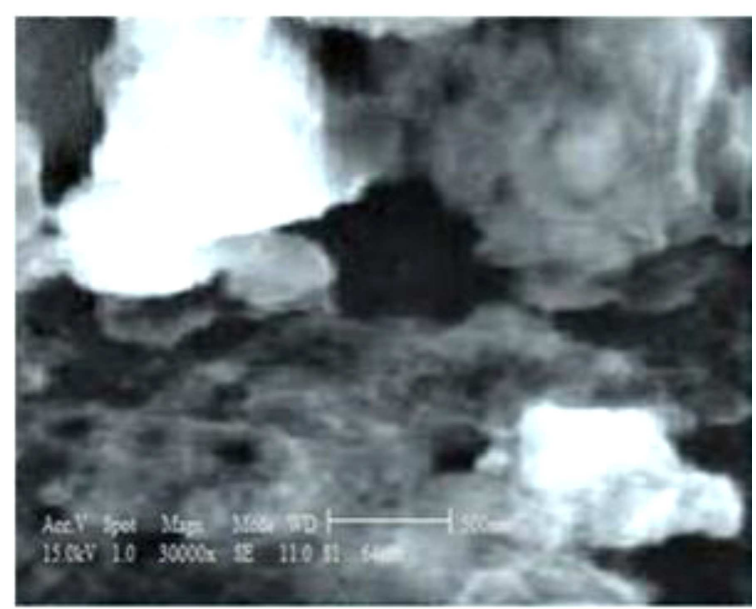

(b)

Figure 1. SEM micrograph of nanometric adsorption nanoparticles of (a) mesquite and (b) aloe vera leaves.

adsorptive property are methylene blue and iodine numbers determined by standard procedures [23]. The aloe vera and mesquite nanoparticles have methylene blue numbers of 130 and 119, respectively. The aloe vera nanoparticle has iodine number of 375 , whereas mesquite nanoparticle has 346 .

\subsection{Effect of $\boldsymbol{p H}$}

The $\mathrm{pH}$ of the solution is considered to be one of the most important parameters in adsorption processes, affecting the surface charge of the adsorbent as well as the degree of ionization and speciation of the adsorbate $[24,25]$. In order to evaluate the effect of $\mathrm{pH}$ on the adsorption of phenol on nano bioadsorbents, the adsorption experiments were carried out with $8 \mathrm{mgL}^{-1}$ phenol concentration, $0.08 \mathrm{gL}^{-1}$ nano-bioadsorbent dose, and $40 \mathrm{~min}$ contact timeat $35^{\circ} \mathrm{C}$ at different initial $\mathrm{pH}$ values in the range of $3-11$ (Figure 2). Figure 2 shows the effects of $\mathrm{pH}$ on phenol adsorption in aloe vera and mesquite nanoparticles, where an increase in $\mathrm{pH}$ up to 7 would lead to adsorption efficiency of up

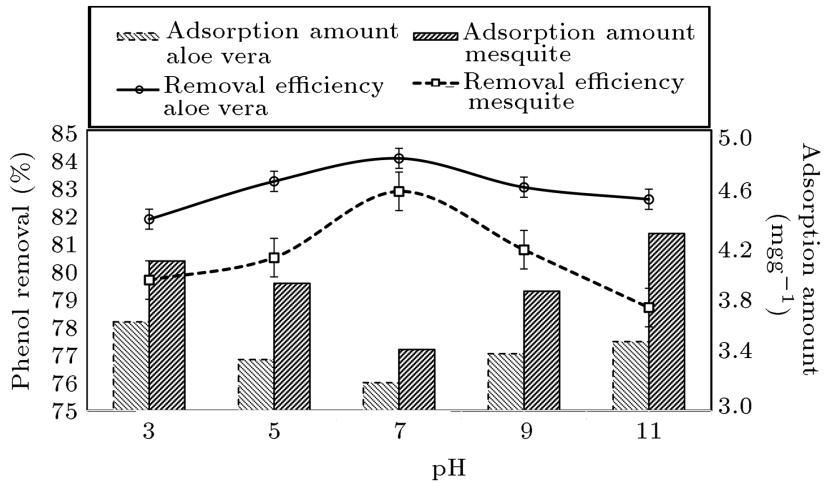

Figure 2. Effect of pH on phenol adsorption by mesquite and aloe vera nanoparticles. Condition: The initial concentration of phenol: $8 \mathrm{mgL}^{-1}$, nano-bioadsorbent dosage: $0.08 \mathrm{gL}^{-1}$, and contact time: $40 \mathrm{~min}$.

to $84 \%$ and $82 \%$ for both nanoparticles, respectively. As the $\mathrm{pH}$ is increasing to 11, adsorption amount increases gradually, whereas adsorption efficiency tends to decrease. The minimum adsorption capacities of nanoparticles of aloe vera and mesquite at $\mathrm{pH} 7$ were equal to $3.2 \mathrm{mgg}^{-1}$ and $3.4 \mathrm{mgg}^{-1}$, respectively. The optimum amount of adsorption was determined at $\mathrm{pH} 7$ for both nano-bioadsorbents due to the difference in the concentrations of $\mathrm{H}^{+}$and $\mathrm{OH}^{-}$in the solutions.

At lower $\mathrm{pH}$ values, the adsorption of phenol is less likely to happen due to both the presence of $\mathrm{H}^{+}$ions and increased $\mathrm{H}^{+}$adsorption on the carbonyl sites, suppressing phenol adsorption [26]. At higher $\mathrm{pH}$ range, the ionization degree of phenol increases and phenol forms salts, readily ionizing and causing negative charge on the phenolic group. Simultaneously, the quantity of $\mathrm{OH}^{-}$ions also increases. Thereby, the presence of $\mathrm{OH}^{-}$ions on the adsorbent hampers and the diffusion/uptake of phenolic ions increase the electrostatic repulsion between the negatively charged surface sites of the adsorbent and phenolate ions. These results are in line with the findings of the previous studies. Banat et al. (2000), for example, reported that in the presence of bentonite, the proportion of phenol adsorption is decreased by increasing $\mathrm{pH}$ [27]. A similar study by Senel et al. showed that when using hollow fibers, the maximum removal rate of both phenol and chlorophenols pollutants from water was observed at $\mathrm{pH} 2$, and no significant decrease was found in the adsorption capacity when $\mathrm{pH}$ increased to 6 [1]. Likewise, the study showed that when using low-cost adsorbents (coconut fiber activated carbon), the removal efficiency of phenolic compounds [2-chlorophenol (2-CP)] from solution decreased from $50 \%$ to $15 \%$. The removal efficiency of phenolic compounds $[2,4$, 6-trichlorophenol (TCP)] also decreased from 55\% to $19 \%$. Using acid treated coconut fiber activated carbon for the removal of $2-\mathrm{CP}$ showed a decline from $58 \%$ to $23 \%$; for the removal of TCP, a decrease from $78 \%$ to 
$30 \%$ was revealed due to changes in $\mathrm{pH}$ from 2 to 10 [28]. PH 7.0 was selected as an optimum $\mathrm{pH}$ value from the experimental results.

\subsection{The effect of nano-bioadsorbent dosage}

In any adsorption process, another important parameter is the amount of adsorbent that plays an important role. This parameter determines the capacity of adsorbent for a given phenol concentration and also determines sorbent-sorbate equilibrium of the system [29]. Thus, the study of a wide range of aloe vera and mesquite nano-bioadsorbents dosage at constant conditions showed that phenol removal from the solution depends on the dosage of adsorbent in the solution. The result of the study demonstrates that as the dosage of nanoparticles of aloe vera and mesquite increases, the amount of solute adsorbed increases and reaches a maximum value corresponding to a certain dosage (Figure 3). This can be observed in Figure 3 . For nanoparticles of aloe vera and nanoparticles of mesquite, phenol removal reached $97.13 \%$ and $86.2 \%$, respectively, when their dosage was $0.08 \mathrm{gL}^{-1}$ and the initial phenol concentration was $8 \mathrm{mgL}^{-1}$. As nano-bioadsorbent dosage increases at a fixed phenol, the initial concentration provides greater availability for the exchangeable sites or surface area for phenol; hence, the removal has enhanced, whereas the adsorption amount has decreased due to the partial aggregation or overlapping of nanoparticles of aloe vera and mesquite, resulting in a less effective surface area for the adsorption. Beyond a certain dosage, the adsorption efficiency did not increase significantly. In other words, the system has reached equilibrium, indicating that the adsorption and desorption rate of phenol is equal [30]. In addition, nanoparticles have high reactivity due to its high specific surface area, and by increasing the amount of adsorbent solution (up to $0.08 \mathrm{gL}^{-1}$ ), the particles interact with each other instead of adsorbing pollutants and convert to hunk. In this case, the specific surface area reduced,

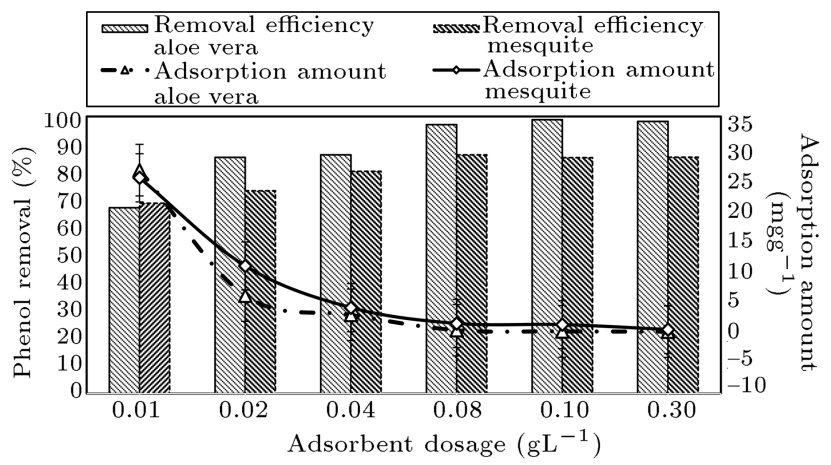

Figure 3. Effect of mesquite and aloe vera nanoparticles dosage on phenol adsorption. Condition: $\mathrm{pH}$ : 7.0, the initial concentration of phenol: $8 \mathrm{mgL}^{-1}$, and contact time: $40 \mathrm{~min}$. and then the efficiency of adsorption of pollutants reduced by these particles [31]. Therefore, the optimum amounts of nanoparticles of aloe vera and mesquite for further adsorption experiments were selected $0.08 \mathrm{gL}^{-1}$ for both nano-bioadsorbents. Rengaraj et al. (2002) conducted one study on the adsorption of phenol from water and wastewater using activated carbon produced from palm kernel, and observed that phenol removal efficiency increased up to the optimum adsorbent dosage of $1 \mathrm{mgL}^{-1}$ [32]. Sarkar and Acharya, in another research, studied on the phenol removal and its derivatives from the contaminated water using fly ash optimum adsorbent dosage of $0.02 \mathrm{mgL}^{-1}$ [33].

\subsection{The effect of particle size of the nano-bioadsorbent}

The size of particle provides valuable information on achieving optimum usage of adsorbent and adsorption capacity [34]. Particle size of $95 \mathrm{~nm}$ was applied to the adsorption kinetic experiment of this study to remove phenol. The smaller the adsorbent particles, the faster the diffusion, because more tiny pores are exposed to adsorbate molecules. In addition, the existence of large number of smaller particles would provide the adsorption system with a greater surface area for adsorption of phenol from the solution. The adsorption capacity is directly proportional to the total surface area exposed, whereas it is inversely proportional to the particle size diameter for non-porous adsorbents $[35,36]$. In a study conducted by Roostaei and Tezel (2004) on phenol removal through the adsorption using silica gel, HiSiv ${ }^{\mathrm{TM}}$ 3000, activated alumina, activated carbon, Filtrasorb400 , and $\mathrm{HiSiv}^{\mathrm{TM}} 1000$, it was revealed that powdered HiSiv $^{\mathrm{TM}} 1000$ (particle size $<100 \mu \mathrm{m}$ ) has the best kinetics result with the highest rate of adsorption [37]. Sarkar and Acharya (2006) conducted another study on the removal of phenol and its derivatives using fly ash. The results showed that by resizing the adsorbent particle from 0.125 to $0.053 \mathrm{~mm}$, the adsorption of phenol, 1,2-dihydroxy benzene, 1,3-dihydroxy benzene, and 4-nitrophenol increased from $31 \%$ to $70 \%, 19 \%$ to $40 \%, 22 \%$ to $48 \%$, and $26 \%$ to $56 \%$, respectively [33].

\subsection{The effect of initial concentration of phenol}

The experiment's findings depicted in Figure 4 demonstrate that phenol adsorption is a function of initial concentration. The maximum phenol removal efficiency of both nano-bioadsorbents was found at initial concentration of $32 \mathrm{mgL}^{-1}$. In other words, the highest removal efficiency was equivalent to $99.4 \%$ and $98.65 \%$ for aloe vera and mesquite nanoparticles, respectively, where the rate of phenol removal decreased with higher concentrations. This efficiency reduction is due to a decrease in the number of available active sites on the surface of the adsorbent and the saturation of these 


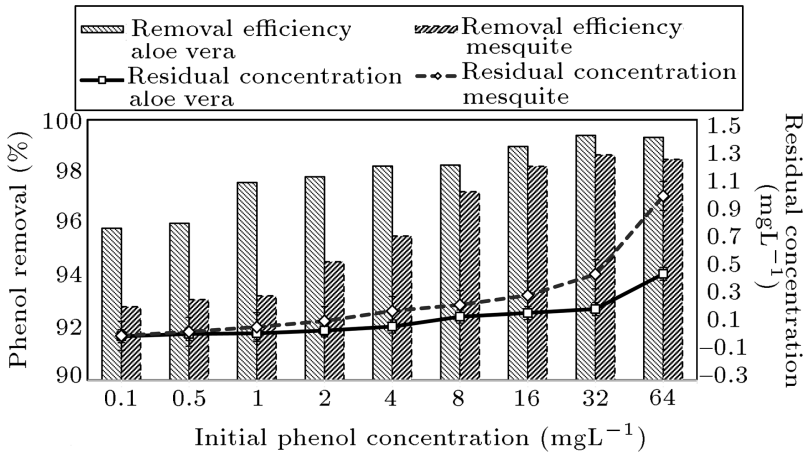

Figure 4. Effect of initial phenol concentration on its adsorption. Condition: $\mathrm{pH}$ : 7.0, nano-bioadsorbent dosage: $0.08 \mathrm{gL}^{-1}$, and contact time: $40 \mathrm{~min}$.

locations on the adsorbent surface. Inefficient removal of phenol in higher concentrations can be related to the reduced rate of mass transfer and subsequent reduction in adsorption capacity $[32,38]$. Differences between aloe vera and mesquite as nano-bioadsorbents revealed that the efficiency of phenol removal has greatly increased by mesquite with a steeper slope than aloe vera, whereas both nano-bioadsorbents had the maximum adsorbent capacity at the initial concentration of $32 \mathrm{mgL}^{-1}$ of phenol. The increases in the level of phenol solution were shown to reduce the removal efficiency. This study also showed that adsorption capacity moved upward with increasing concentrations of phenol, and the maximum adsorbent capacity was obtained at initial concentration of $64 \mathrm{mgL}^{-1}$ of phenol. In a study conducted by Mahvi et al. (2004) on the application of agricultural waste to remove phenol from aqueous environment, it was found that ash of rice bran had higher capacity (98\%) for phenol adsorption than the rice bran (44\%), and that the adsorption capacity of adsorbent was raised by increasing the initial concentration of phenol [39]. Similarly, Saitoh et al. (2011) investigated the phenol removal from water by applying bonded chitosan to heated polymers, and found that the removal efficiency remains constant by increasing phenol concentrations from 0.2 to $0.3 \mathrm{mM}$; however, it is still reduced by increasing the phenol concentrations from 0.3 to $1 \mathrm{mM}$ [40].

\subsection{The effect of contact time}

Adsorption capacity decreased with increasing the contact time in both nano-bioadsorbents, where it reached the lowest value ( 0.4 and $1.86 \mathrm{mgg}^{-1}$ for aloe vera and mesquite, respectively) with increasing the time up to $90 \mathrm{~min}$. The rate of removal was speedier at the beginning of reaction. According to Figure 5, the maximum efficiency of phenol removal happened within $60 \mathrm{~min}$, and these values were 99.32 and $95.2 \%$ for both aloe vera and mesquite nanoparticles, respectively. The system, however, reached an equilibrium state after this time period with no significant increase

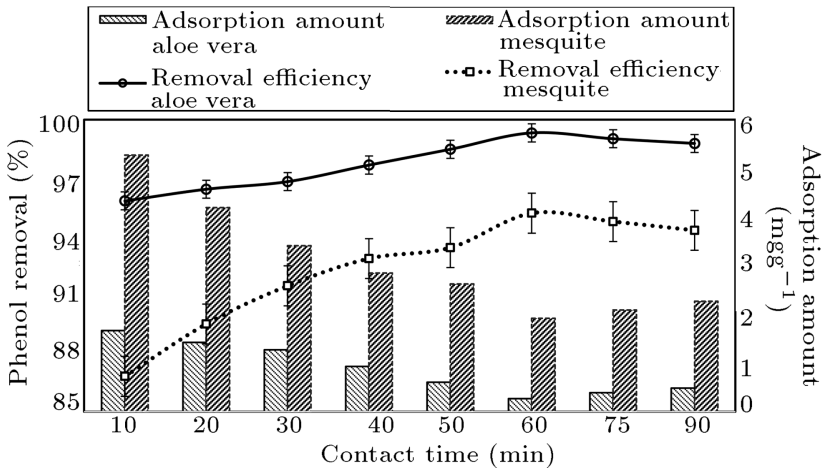

Figure 5. Effect of contact time on phenol adsorption. Condition: $\mathrm{pH}$ : 7.0, nano-adsorbent dosage: $0.08 \mathrm{gL}^{-1}$, and phenol concentration: $32 \mathrm{mgL}^{-1}$.

in the removal efficiency. Phenol reduction in the solution did not increase by rising the contact time between nano-bioadsorbents and phenol. Such an increase in removal efficiency is due to more empty sites available for phenol adsorption at shorter contact times where the phenol contact increases with empty sites. The phenol in solution occupied the empty sites until $60 \mathrm{~min}$ passed, and the removal efficiency reached its maximum capacity [34,41]. In their study, Mohanty et al. (2005) used activated carbon produced from sawdust tree in tropical regions, and found that the phenol adsorption and phenol removal efficiency increased from $36 \%$ to $63 \%$ by increasing contact time from 20 to $180 \mathrm{~min}$ [42]. In another study, Gutierrez et al. (2012) evaluated the usage of copper slag to catalyze the advanced oxidation processes for phenol removal from water, and it was revealed that the application of $\mathrm{UV} / \mathrm{H}_{2} \mathrm{O}_{2} /$ copper slag and $\mathrm{H}_{2} \mathrm{O}_{2}$ /copper slag reduced phenol at 30 and 90 min time intervals, respectively. However, the removal of phenol in up to 120 min was not considerable [43].

\subsection{The effect of temperature}

Figure 6 shows that the removal efficiency of phenol on nano-bioadsorbents increases with increasing tem-

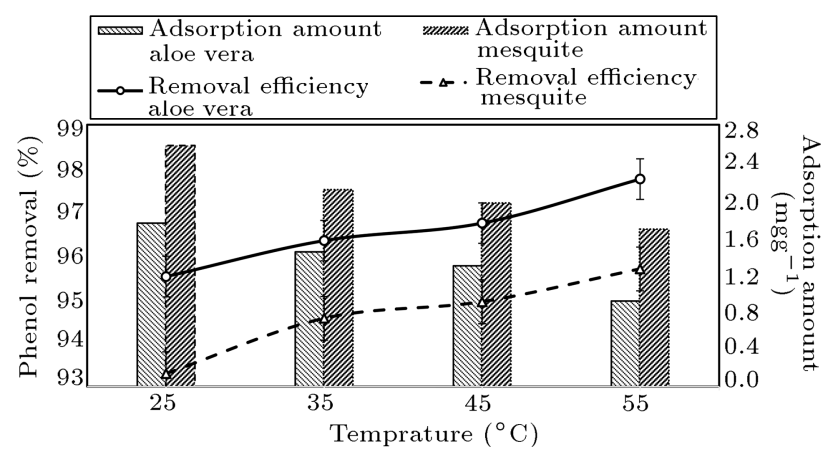

Figure 6. Effect of temperature on phenol adsorption. Condition: $\mathrm{pH}$ : 7.0, nano-bioadsorbent dosage: $0.08 \mathrm{gL}^{-1}$, and phenol concentration: $32 \mathrm{mgL}^{-1}$, and contact time: $40 \mathrm{~min}$. 
perature, particularly when the temperature increases from 25 to $55^{\circ} \mathrm{C}$. The removal rate was the highest at $55^{\circ} \mathrm{C}$ where $97.62 \%$ and $95.62 \%$ of phenol were removed by aloe vera and mesquite nanoparticle, respectively. The increase in removal efficiency together with increased temperature can be caused by the expansion of adsorbent and increases in active sites available for phenol adsorption [44]. The $2 \%$ difference could be due to aloe vera available sites being available more than the mesquite sites. Similar findings have been obtained by the studies conducted on pollutant removals. Examples include the biological phenol adsorption using chicken feathers conducted by Qadeer, Indigo Carmine dye adsorption by poultry feathers carried out by Mittal, and Lead adsorption by applying chicken feathers done by Dela Rosa [45-47]. Srivastava et al. conducted a similar study (2006) on the phenol removal by bagasse fly ash and activated carbon. The results showed that phenol adsorption increases by an increase in temperature from 25 to $45^{\circ} \mathrm{C}$ [48], but another study by Kilic et al. (2011) on phenol removal, by the activated carbon prepared from residues of tobacco, indicated that adsorption efficiency decreased by increasing temperature from 20 to $50^{\circ} \mathrm{C}$ [49].

\subsection{Effects of ionic strength}

In the present study, $\mathrm{NO}_{3}^{-}, \mathrm{Cl}^{-}, \mathrm{SO}_{4}^{2-}$, and $\mathrm{HCO}_{3}^{-}$ions in the form of $\mathrm{NaNO}_{3}, \mathrm{NaCl}, \mathrm{Na}_{2} \mathrm{SO}_{4}$, and $\mathrm{NaHCO}_{3}$ were separately used to evaluate the effect of ionic strength (0.01-0.25 M concentrations) of the solution on the phenol removal through aloe vera and mesquite nanoparticles. The results are shown in Figures 7 and 8. Experimental findings indicate that an increase in the salt concentration resulted in a decrease of phenol adsorption by nanoparticles obtained from aloe vera and mesquite, in that when the concentration of salts within the aloe vera nanoparticles increased from 0 to $0.25 \mathrm{M}$, the percentage of removal efficiency decreased from $99.4 \%$ to $18.62 \%, 27.15 \%, 32.19 \%$, and $39.68 \%$ with $\mathrm{NaNO}_{3}, \mathrm{NaCl}, \mathrm{Na}_{2} \mathrm{SO}_{4}$, and $\mathrm{NaHCO}_{3}$

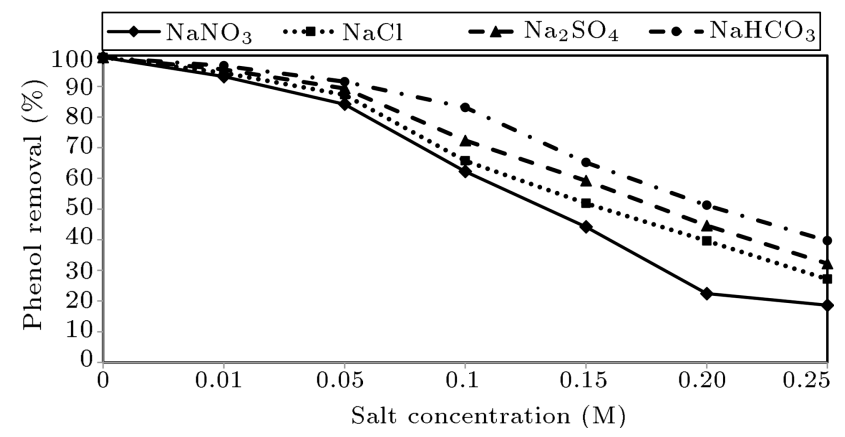

Figure 7. Effect of ionic strength on the phenol adsorption by using nanoparticles aloe vera. Condition: pH: 7.0, initial phenol conc.: $32 \mathrm{mgL}^{-1}$, nano-bioadsorbent dosage: $0.08 \mathrm{gL}^{-1}$, and contact time: $40 \mathrm{~min}$.

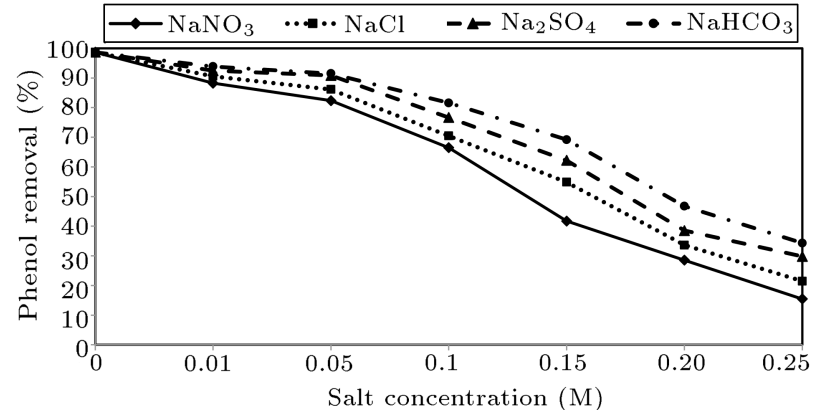

Figure 8. Effect of ionic strength on the phenol adsorption by using nanoparticles aloe vera. Condition: pH: 7.0, initial phenol conc.: $32 \mathrm{mgL}^{-1}$, nano-bioadsorbent dosage: $0.08 \mathrm{gL}^{-1}$, and contact time: $40 \mathrm{~min}$.

salts, respectively. Likewise, with an increase in the concentration of salts within mesquite nanoparticles from 0 to $0.25 \mathrm{M}$, the phenol removal efficiency has decreased from $98.67 \%$ to $15.46 \%, 21.47 \%, 29.81 \%$, and $34.32 \%$ with $\mathrm{NaNO}_{3}, \mathrm{NaCl}, \mathrm{Na}_{2} \mathrm{SO}_{4}$, and $\mathrm{NaHCO}_{3}$ salts, respectively.

The negative effect of $\mathrm{NO}_{3}^{-}$and $\mathrm{Cl}^{-}, \mathrm{SO}_{4}^{2-}$ and $\mathrm{HCO}_{3}^{-}$could be explained by the fact that the adsorbent active sites may have been blocked by salt, which in turn, has resulted in increasing the hindrance of phenol diffusion on the adsorbent surfaces. The decrease in adsorption with increased ionic strength may be also due to the decrease in hydrophobic nature of the dissociated phenol molecules at pH $2.0[2,50]$. Our findings showed that the $\mathrm{NaNO}_{3}$ salt exhibited a higher inhibition of phenol adsorption compared with $\mathrm{NaCl}, \mathrm{Na}_{2} \mathrm{SO}_{4}$, and $\mathrm{NaHCO}_{3}$ salts. These findings are consistent with those of the study conducted by Senturk et al. on the phenol removal from aqueous solutions by adsorption on organomodified Tirebolu bentonite, and also the work of Mukherjee et al. on the removal of phenols from water environment by activated carbon, bagasse ash, and wood charcoal $[2,50]$.

\subsection{Adsorption isotherm}

Equilibrium isotherms are the most important parameters in designing the adsorption process, referring, in this case, to the amount of adsorption on nanobioadsorbent reaching equilibrium state. In fact, we can use the adsorption isotherm to determine the maximum adsorption and also the optimum conditions of the optimal adsorption. Analysis of adsorption isotherm is essential for achieving equation in order to show accurate results and design the adsorption systems $[51,52]$. In this study, two well-known models, i.e. Langmuir and Freundlich isotherm models, were chosen for evaluating the relationship between the amount of phenol adsorbed onto bio-adsorbents' nanoparticles and its equilibrium concentration in aqueous solution.

The Langmuir model assumes that adsorption occurs at specific homogeneous sites on the adsorbent 
surface. It also assumes that when a site is occupied by an adsorbate molecule, no more adsorption takes place at this site. The linear form of the Langmuir isotherm model can be presented as in Eq. (3) [35,36], where $q_{e}$ is the equilibrium adsorption capacity of phenol on the adsorbent $\left(\mathrm{mgg}^{-1}\right), C_{e}$ is the equilibrium dye concentration in solution $\left(\mathrm{mgL}^{-1}\right), q_{m}$ is the maximum capacity of the adsorbent $\left(\mathrm{mgg}^{-1}\right)$, and $k_{L}$ is the Langmuir adsorption constant $\left(\mathrm{Lmg}^{-1}\right)$ :

$$
\frac{C_{e}}{q_{e}}=\frac{C_{e}}{q_{m}}+\frac{1}{q_{m} K_{L}} .
$$

A dimensionless constant $\left(R_{L}\right)$ is also defined as a separation factor or equilibrium parameter derived from the Langmuir isotherm in accordance with the following equation. $R_{L}$ is supposed to determine the optimal ability of phenol adsorption process on nanoparticles prepared from the agricultural waste $[36,40]$ :

$$
R_{L}=\frac{1}{\left(1+K_{l} C_{0}\right)},
$$

where $C_{0}\left(\mathrm{mgL}^{-1}\right)$ is the initial amount of adsorbate and $K_{l}\left(\mathrm{Lmg}^{-1}\right)$ is the Langmuir constant described above. $R_{L}$ parameter is considered as a reliable indicator of the adsorption. The Freundlich isotherm model is valid for multi-layer adsorption on a heterogeneous adsorbent surface with sites that have different energies of adsorption. The Freundlich model in linear form is presented as in Eq. (5) [43]:

$$
\ln q_{e}=\ln k_{f}+\frac{1}{n} \ln C_{e},
$$

where $K_{f}\left(\mathrm{mgg}^{-1}\right)$ is the constant related to the adsorption capacity, and $n$ is the empirical parameter related to the intensity of adsorption.

Physically, Freundlich model provides more reliable descriptions for pollutants adsorbent than Langmuir model which can be explained by the presence of different adsorption bands on adsorbent [53,54]. Table 2 shows the results of the correlation and constants of the two Freundlich and Langmuir models. According to these findings, isothermal information indicates that Freundlich equation describes a better understanding of phenol adsorption by the nanobioadsorbent than the Langmuir isotherm, mainly because of higher correlation coefficient (more than 0.95 for both nano-bioadsorbents). According to $R_{L}$, the adsorption process can be irreversible $\left(R_{L}=\right.$ $0)$, optimal $\left(0<R_{L}<1\right)$, Linear $\left(R_{L}=1\right)$ or unfavorable $\left(R_{L}>1\right)$ [50]. The calculated RL value for phenol adsorption derived from the nanoparticles of the agricultural solid waste (leaves of the aloe vera plant and mesquite trees) was between zero and one, indicating desirability of phenol adsorption in adsorbents examined. These findings are consistent with the results of Mukherjee et al. (2007) who studied the phenol removal from water by activated carbon, bagasse ash and charcoal, and the results of Potgieter et al. (2009) who carried out another study on fly ash of coal. In line with these studies, we found that the adsorption of phenol by adsorbents better fits into Freundlich isotherms model [50,55]. Yet another study conducted by Srivastava et al. (2006) showed better results of phenol adsorption by the adsorbent [48]. These varied findings show that a single model cannot be provided for pollutants adsorption by adsorbents, and that choosing an acceptable adsorption model depends on the types of pollutants and adsorbents used in the process.

\subsection{The adsorption kinetics}

Understanding the notion of the adsorption kinetics is also important for the mechanisms of adsorption and detection of adsorbents performance. In the current study, different Kinetic models were used for obtaining experimental results, including pseudo-firstorder and pseudo-second-order adsorption kinetics [25]. The pseudo-first-order equation is shown in Eq. (6) [50]:

$$
\ln \left(q_{e}-q_{t}\right)=\ln \left(q_{e}\right)-K_{1} \times t,
$$

where $q_{e}\left(\mathrm{mgg}^{-1}\right)$ and $q_{t}\left(\mathrm{mgg}^{-1}\right)$ are the amounts of phenol adsorbed at equilibrium at time $t$, and $k_{1}$ $\left(\min ^{-1}\right)$ is the pseudo-first-order rate constant.

A straight line $\ln \left(q_{e}-q_{t}\right)$ versus $t$ expresses the applicability of this kinetic model; $q_{e}$ and $K_{1}$ can be determined from the intercept and slope of the plot. Pseudo-second-order model is expressed as follows [52]:

$$
\frac{t}{q_{t}}=\frac{1}{k_{2} \times q_{e}^{2}}+\frac{t}{q_{e}},
$$

where $k_{2}\left(\mathrm{gmg}^{-1} \mathrm{~min}^{-1}\right)$ is the rate constant of the second-order equation.

Table 2. Isotherm parameters for the removal of phenol by aloe vera and mesquite as nanoparticles.

\begin{tabular}{ccccccccc}
\hline & & \multicolumn{2}{c}{ Langmuir } & \multicolumn{4}{c}{ Freundlich } \\
\cline { 3 - 8 } $\begin{array}{c}\text { Bioadsorbent } \\
\text { nanoparticles }\end{array}$ & $\mathbf{Q}_{\mathbf{0}}\left(\mathbf{m g g}^{-\mathbf{1}}\right)$ & $\boldsymbol{K}_{\boldsymbol{L}}\left(\mathbf{L} \mathbf{~ m g}^{-\mathbf{1}}\right)$ & $\boldsymbol{R}^{\mathbf{2}}$ & $\boldsymbol{R}_{\boldsymbol{L}}$ & $\boldsymbol{K}_{\boldsymbol{f}}$ & $\boldsymbol{R}^{\mathbf{2}}$ & $\boldsymbol{n}$ \\
\hline Aloe vera & 71.73 & 0.53 & 0.9 & 0.055 & 25.51 & 2.16 & 0.97 \\
Mesquite & 54.27 & 7.31 & 0.79 & 0.004 & 45.89 & 4.09 & 0.95 \\
\hline
\end{tabular}


Table 3. Kinetic parameters for the removal of phenol by aloe vera and mesquite as nanoparticles.

\begin{tabular}{cccccccc}
\hline & & \multicolumn{2}{c}{ Pseudo first-order model } & \multicolumn{2}{c}{ Pseudo second-order model } \\
\cline { 3 - 8 } $\begin{array}{c}\text { Bioadsorbent } \\
\text { nanoparticles }\end{array}$ & $\boldsymbol{q}_{\text {e.exp }}\left(\mathbf{m g g}^{-\mathbf{1}}\right)$ & $\boldsymbol{K}_{\mathbf{1}}\left(\mathbf{m i n}^{-\mathbf{1}}\right)$ & $\boldsymbol{q}_{\text {e.exp }}\left(\mathbf{m g g}^{-\mathbf{1}}\right)$ & $\boldsymbol{R}^{\mathbf{2}}$ & $\boldsymbol{k}_{\mathbf{2}}\left(\mathrm{g} \mathrm{mg}^{-\mathbf{1}} \mathbf{m i n}^{-\mathbf{1}}\right)$ & $\boldsymbol{q}_{\mathrm{e} . \exp }\left(\mathbf{m g g}^{-\mathbf{1}}\right)$ & $\boldsymbol{R}^{\mathbf{2}}$ \\
\hline $\begin{array}{c}\text { Alo vera } \\
\text { Mesquite }\end{array}$ & 2.66 & 0.033 & 0.05 & 0.458 & 0.04 & 1.87 & 0.793 \\
\hline
\end{tabular}

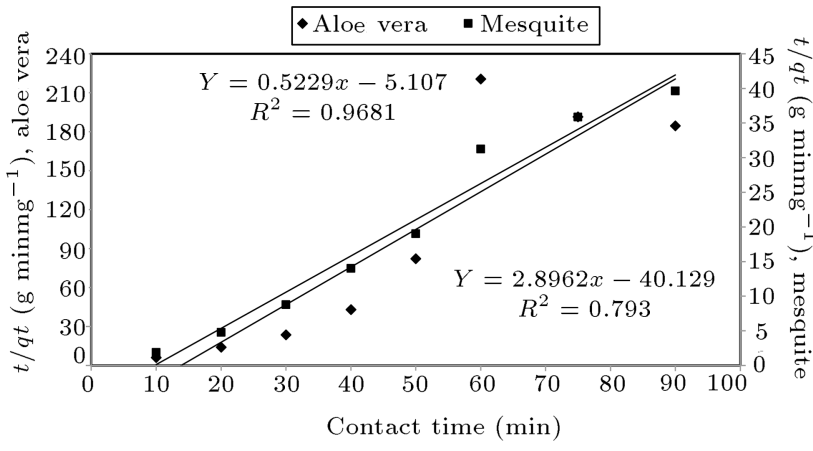

Figure 9. The pseudo-second-order kinetics for phenol adsorption by aloe vera and mesquite as nanoparticles.

The plot of $t / q_{t}$ versus $t$ would create a straight line if the pseudo-second-order kinetic model was applicable, where $q_{e}$ and $K_{2}$ can be determined from the slope and interception of the plot. The rate constant of pseudo-first-order $\left(K_{1}\right)$ and the calculated concentration of adsorbate of solid phase in equilibrium conditions $\left(q_{e, \text { cal }}\right)$ were calculated through $\ln \left(q_{e}-q_{t}\right)$ plot versus $t$. The results are shown in Table 3 . The correlation coefficient $\left(R^{2}\right)$ was relatively low, which may indicate an inappropriate relationship. In addition, the amount of $q_{e, \text { cal }}$ from the model is very different from the concentration of adsorbate amount of solid phase in the equilibrium conditions $\left(q_{e, \exp }\right)$. The phenol adsorption by bioadsorbents nanoparticles through pseudo-first-order model is thus inappropriate. The linear plot $\left(t / q_{e}\right)$ versus $t$ is shown in Figure 9 for the pseudo-second-order. The rate constant of pseudo-second-order $\left(K_{2}\right)$ and amount of $q_{e, \text { cal }}$ were determined through the model, and the results are shown in Table 3 . The correlation coefficient $\left(R^{2}\right)$ was high, and the calculated amount of $q_{e, \text { cal }}$ was close to the amount of $q_{e, \text { exp }}$. According to these results, Pseudo-second-order kinetics model is well correlated with phenol adsorption by bioadsorbents nanoparticles than using pseudo-first-order model. Senturk et al. (2009) studied the phenol removal from aqueous environments through adsorption by bentonite. Najam Khan et al. (2015) investigated the phenol removal by photocatalytic activity of zinc stannate particles and zinc stannate/zinc oxide composites. In addition, Gundogdu et al. (2012) investigated the ability of activated carbon produced from Tea industry waste in the adsorption of phenol. The results of this study are consistent with those reported by these authors $[1,2,56]$.

\section{Conclusions}

The adsorption ability of nanoparticles obtained from the leaves of aloe vera plant and mesquite trees was investigated to explore the removal of phenol from aqueous solutions. The results indicated that aloe vera and mesquite nanoparticles are efficient as promising adsorbents in removing phenol from solution. A phenol removal efficiency of more than $96 \%$ was achieved under optimum conditions $(\mathrm{pH}=7$, adsorbent dosage $=$ $0.08 \mathrm{gL}^{-1}$, initial phenol concentration $=32 \mathrm{mgL}^{-1}$, contact time $=60 \mathrm{~min}$ at $55^{\circ} \mathrm{C}$ ) for both nanobioadsorbents. Phenol removal from aqueous environment by bio-adsorbents nanoparticles follows the pseudo-second-order kinetics model. This method can be considered as a suitable method for phenol removal from industrial wastewater, reusing wastewater, reducing the irreversible health and environmental adverse effects of phenol, and the possibility of producing lowcost aloe vera and mesquite nanoparticles.

\section{Acknowledgment}

This study was approved by the Environmental Health Engineering Research Center of Kerman University of Medical Sciences (Grant code no. 93/412), and conducted with the financial support of the Deputy for Research and Technology of Kerman University of Medical Sciences, Kerman, Iran.

\section{References}

1. Najam Khan, M. and Dutta, J. "Comparison of photocatalytic activity of zinc stannate particles and zinc stannate/zinc oxide composites for the removal of phenol from water, and a study on the effect of pH on photocatalytic efficiency", Materials Science in Semiconductor Processing, 36, pp. 124-133 (2015).

2. Senturk, H.B., Ozdes, D., Gundogdu, A., Duran, C. and Soylak, M. "Removal of phenol from aqueous 
solutions by adsorption onto organomodified Tirebolu bentonite: Equilibrium, kinetic and thermodynamic study", Journal of Hazardous Materials, 172(1), pp. 353-362 (2009).

3. Singh, J., Lingamdinne, L.P., Yang, J.-K., Chang, Y.-Y., Lee, B.-K. and Koduru, J.R. "Effect of $\mathrm{pH}$ values on recovery of nano particles (NPs) from the fine fraction of automobile shredder residue (ASR): An application of NPs for phenol removal from the water", Process Safety and Environmental Protection, 105, pp. 51-59 (2017).

4. Vasudevan, S. "An efficient removal of phenol from water by peroxi-electrocoagulation processes", Journal of Water Process Engineering, 2, pp. 53-57 (2014).

5. Bayramoglu, G. and Arica, M.Y. "Enzymatic removal of phenol and p-chlorophenol in enzyme reactor: Horseradish peroxidase immobilized on magnetic beads", Journal of Hazardous Materials, 156(1), pp. 148-155 (2008).

6. Cantarella, M. Sanz, R. Buccheri, M.A. Ruffino, F. Rappazzo, G. Scalese, S. Impellizzeri, G., Romano, L. and Privitera, V. "Immobilization of nanomaterials in PMMA composites for photocatalytic removal of dyes, phenols and bacteria from water", Journal of Photochemistry and Photobiology A: Chemistry, 321, pp. 1-11 (2016).

7. Gupta, A. and Balomajumder, C. "Removal of $\mathrm{Cr}(\mathrm{VI})$ and phenol using water hyacinth from single and binary solution in the artificial photosynthesis chamber", Journal of Water Process Engineering, 7, pp. 74-82 (2015).

8. Ali, I., Asim, M. and Khan, T.A. "Low cost adsorbents for the removal of organic pollutants from wastewater", Journal of Environmental Management, 113, pp. 170183 (2012).

9. Dezuane, J. Hand Book of Drinking Water Quality, Van Nos Trand Reinhold (1997).

10. Busca, G., Berardinelli, S., Resini, C. and Arrighi, L. "Technologies for the removal of phenol from fluid streams: A short review of recent developments", Journal of Hazardous Materials, 160(2), pp. 265-288 (2008).

11. Hank, D., Azi, Z., Ait Hocine, S., Chaalal, O. and Hellal, A. "Optimization of phenol adsorption onto bentonite by factorial design methodology", Journal of Industrial and Engineering Chemistry, 20(4), pp. 2256-2263 (2014).

12. Moussavi, G., Mahmoudi, M. and Barikbin, B. "Biological removal of phenol from strong wastewaters using a novel MSBR", Water Research, 43(5), pp. 1295-1302 (2009).

13. De Silva, C.L., Garlapalli, R.K. and Trembly, J.P. "Removal of phenol from oil/gas produced water using supercritical water treatment with $\mathrm{TiO}_{2}$ supported $\mathrm{MnO}_{2}$ catalyst", Journal of Environmental Chemical Engineering, 5(1), pp. 488-493 (2017).
14. Yadav, A., Teja, A.K. and Verma, N. "Removal of phenol from water by catalytic wet air oxidation using carbon bead-supported iron nanoparticle-containing carbon nanofibers in an especially configured reactor," Journal of Environmental Chemical Engineering, 4(2), pp. 1504-1513 (2016).

15. Sathishkumar, M., Binupriya, A.R., Kavitha, D., Selvakumar, R., Sheema, K.K., Choi, J.G. and Yun, S.E. "Organic micro-pollutant removal in liquid-phase using carbonized silk cotton hull", Journal of Environmental Sciences, 20(9), pp. 1046-1054 (2008).

16. Shao, A., Broadmeadow, A., Goddard, G., Bejar, E. and Frankos, V. "Safety of purified decolorized (low anthraquinone) whole leaf aloe vera (L) Burm. f. juice in a 3-month drinking water toxicity study in F344 rats", Food and Chemical Toxicology, 57, pp. 21-31 (2013).

17. Yang, G. Tang, L. Zeng, G. Cai, Y. Tang, J. Pang, Y. Zhou, Y., Liu, Y., Wang, J., Zhang, S. and Xiong, W. "Simultaneous removal of lead and phenol contamination from water by nitrogen-functionalized magnetic ordered mesoporous carbon", Chemical Engineering Journal, 259, pp. 854-864 (2015).

18. Senthilkumar, P., Prince, W.S., Sivakumar, S. and Subbhuraam, C.V. "Prosopis juliflorai-A green solution to decontaminate heavy metal ( $\mathrm{Cu}$ and $\mathrm{Cd})$ contaminated soils", Chemosphere, 60(10), pp. 14931496 (2005).

19. Federation, APHA, AWWA, WEF "Standard method for examination of water and wastewater", 2340, 20th Edn., Washington DC, USA (1999).

20. Afkhami, A., Saber-Tehrani, M. and Bagheri, H. "Simultaneous removal of heavy-metal ions in wastewater samples using nano-alumina modified with 2,4dinitrophenylhydrazine", Journal of Hazardous Materials, 181(1), pp. 836-844 (2010).

21. El-Naas, M.H., Al-Zuhair, S. and Alhaija, M.A. "Removal of phenol from petroleum refinery wastewater through adsorption on date-pit activated carbon", Chemical Engineering Journal, 162(3), pp. 9971005 (2010).

22. Karunarathne, H. D. S. S. and Amarasinghe, B. M. W. P. K. "Fixed bed adsorption column studies for the removal of aqueous phenol from activated carbon prepared from sugarcane bagasse", Energy Procedia, 34, pp. 83-90 (2013).

23. Mantell, C.L. Carbon and Graphite Handbook, New York: Wiley/Interscience Publishers, USA (1968).

24. Khalid, N., Ahmad, S., Toheed, A. and Ahmed, J. "Potential of rice husks for antimony removal", Applied Radiation and Isotopes, 52(1), pp. 31-38 (2000).

25. Xing, R., Wu, L., Fei, Z. and Wu, P. "Mesopolymer modified with palladium phthalocyaninesulfonate as a versatile photocatalyst for phenol and bisphenol A 
degradation under visible light irradiation", Journal of Environmental Sciences (China), 25(8), pp. 168795 (2013).

26. Mortaheb, H.R., Amini, M.H., Sadeghian, F., Mokhtarani, B. and Daneshyar, H. "Study on a new surfactant for removal of phenol from wastewater by emulsion liquid membrane", Journal of Hazardous Materials, 160(2), pp. 582-588 (2008).

27. Banat, F.A., Al-Bashir, B., Al-Asheh, S. and Hayajneh, O. "Adsorption of phenol by bentonite", Environmental Pollution, 107(3), pp. 391-398 (2000).

28. Nayak, P.S. and Singh, B.K. "Removal of phenol from aqueous solutions by sorption on low cost clay",Desalination, 207(1), pp. 71-79 (2007).

29. Zeng, X., Yu, T., Wang, P., Yuan, R., Wen, Q., Fan, Y., Wang, C., She, R. "Preparation and characterization of polar polymeric adsorbents with high surface area for the removal of phenol from water", Journal of Hazardous Materials, 177(1-3), pp. 773-80 (2010).

30. Chakravarty, P., Sarma, N.S. and Sarma, H.P. "Removal of lead(II) from aqueous solution using heartwood of Areca catechu powder", Desalination, 256(1), pp. 16-21 (2010).

31. Rahmani, A., Mousavi, H.Z. and Fazli, M. "Effect of nanostructure alumina on adsorption of heavy metals", Desalination, 253(1), pp. 94-100 (2010).

32. Rengaraj, S., Moon, S.-H., Sivabalan, R., Arabindoo, B. and Murugesan, V. "Agricultural solid waste for the removal of organics: adsorption of phenol from water and wastewater by palm seed coat activated carbon", Waste Management, 22, pp. 543-548 (2002).

33. Sarkar, M. and Acharya, P.K. "Use of fly ash for the removal of phenol and its analogues from contaminated water", Waste Management, 26(6), pp. 559-570 (2006).

34. Khattri, S.D. and Singh, M.K. "Removal of malachite green from dye wastewater using neem sawdust by adsorption", Journal of Hazardous Materials, 167, pp. 1089-1094 (2009).

35. Santhi, T., Manonmani, S., Vasantha, V.S. and Chang, Y.T. "A new alternative adsorbent for the removal of cationic dyes from aqueous solution", Arabian Journal of Chemistry, 9, pp. S466-S474 (2016).

36. Suresh, S., Srivastava, V.C. and Mishra, I.M. "Adsorptive removal of phenol from binary aqueous solution with aniline and 4-nitrophenol by granular activated carbon", Chemical Engineering Journal, 171(3), pp. 997-1003 (2011).

37. Roostaei, N. and Tezel, F.H. "Removal of phenol from aqueous solutions by adsorption", Journal of Environmental Management, 70(2), pp. 157-164 (2004).

38. Abdelkreem, M. "Adsorption of Phenol from Industrial Wastewater Using Olive Mill Waste", APCBEE Procedia, 5, pp. 349-357 (2013).

39. Mahvi, A.H., Maleki, A., and Eslami, A. "Potential of rice husk and rice husk ash for phenol removal in aqueous systems", American Journal Applied Science, 1(4), pp. 321-326 (2004).

40. Saitoh, T., Asano, K. and Hiraide, M. "Removal of phenols in water using chitosan-conjugated thermoresponsive polymers", Journal of Hazardous Materials, 185(2-3), pp. 1369-1373 (2011).

41. Srihari, V. and Das, A. "Comparative studies on adsorptive removal of phenol by three agro-based carbons: Equilibrium and isotherm studies", Ecotoxicology and Environmental Safety, 71(1), pp. 274-283 (2008).

42. Mohanty, K., Das, D. and Biswas, M.N. "Adsorption of phenol from aqueous solutions using activated carbons prepared from Tectona grandis sawdust by $\mathrm{ZnCl}_{2}$ activation", Chemical Engineering Journal, 115(1), pp. 121-131 (2005).

43. Huanosta-Gutierrez, T., F. Dantas, R., RamirezZamora, R.M. and Esplugas, S. "Evaluation of copper slag to catalyze advanced oxidation processes for the removal of phenol in water", Journal of Hazardous Materials, 213, pp. 325-330 (2012).

44. Belaib, F., Meniai, A.H. and Lehocine, M.B. "Elimination of phenol by adsorption onto mineral / polyaniline composite solid support", Energy Procedia, 18, pp. 1254-1260 (2012).

45. De la Rosa, G., Reynel-Avila, H.E., Bonilla-Petriciolet, A., Cano-Rodriguez, I., Velasco-Santos, C. and Martinez-Hernandez, A.L. "Recycling poultry feathers for $\mathrm{Pb}$ removal from wastewater: kinetic and equilibrium studies", Proceedings of World Academy of Science, Engineering and Technology, 30, pp. 10111019 (2008).

46. Mittal, A., Mittal, J. and Kurup, L. "Utilization of hen feathers for the adsorption of Indigo Carmine from simulated effluents", Journal of Environmental Protection Science, 1, pp. 92-100 (2007).

47. Qadeer, R.A. "Study of the Adsorption of Phenol by Activated Carbon from Aqueous Solutions", Turkish Journal of Chemistry, 26(3), pp. 357-361 (2002).

48. Srivastava, V.C., Swamy, M.M., Mall, I.D., Prasad, B. and Mishra, I.M. "Adsorptive removal of phenol by bagasse fly ash and activated carbon: Equilibrium, kinetics and thermodynamics", Colloids and Surfaces A: Physicochemical and Engineering Aspects, 272(12), pp. 89-104 (2006).

49. Kilic, M., Apaydin-Varol, E. and Pütün, A.E. "Adsorptive removal of phenol from aqueous solutions on activated carbon prepared from tobacco residues: Equilibrium, kinetics and thermodynamics", Journal of Hazardous Materials, 189(1-2), pp. 397-403 (2011).

50. Mukherjee, S., Kumar, S., Misra, A.K. and Fan, M. "Removal of phenols from water environment by activated carbon, bagasse ash and wood charcoal", Chemical Engineering Journal, 129(1-3), pp. 133-142 (2007).

51. Huang, J., Wang, X., Jin, Q., Liu, Y. and Wang, $Y$. "Removal of phenol from aqueous solution by adsorption onto OTMAC-modified attapulgite", Journal 
of Environmental Management, 84(2), pp. 229-236 (2007).

52. Malakootian, M., Mansoorian, H.J., Hosseini, A. and Khanjani, N. "Evaluating the efficacy of alumina/carbon nanotube hybrid adsorbents in removing azo reactive red 198 and blue 19 dyes from aqueous solutions", Process Safety and Environmental Protection, 96, pp. 125-137 (2015).

53. Aksu, Z., Acikel, U., Kabasakal, E. and Tezer, S. "Equilibrium modelling of individual and simultaneous biosorption of chromium(VI) and nickel(II) onto dried activated sludge", Water Research, 36(12), pp. 30633073 (2002).

54. Atieh, M.A. "Removal of phenol from water different types of carbon - A comparative analysis", APCBEE Procedia, 10, pp. 136-141 (2014).

55. Potgieter, J.H., Bada, S.O. and Potgieter-Vermaak, S.S. "Adsorptive removal of various phenols from water by South African coal ash", Water SA, 35(1), pp. 8996 (2009).

56. Gundogdu, A., Duran, C., Senturk, H.B., Soylak, M., Ozdes, D., Serencam, H. and Imamoglu, M. "Adsorption of phenol from aqueous solution on a low-cost activated carbon produced from tea industry waste: equilibrium, kinetic, and thermodynamic study", Journal of Chemical and Engineering Data, 57(10), pp. 2733-2743 (2012).

\section{Biographies}

Mohammad Malakootian has more than 30 years' experience in environmental health science and is the author of five books with more than 100 scientific publications. He is one of the pioneers of the field of environmental health science. He is currently the head of sector in Environmental Studies and Action Leader for Knowledge Management, Education and Training at the Environmental Health Engineering Research Center in Kerman, Iran.

Hossein Jafari Mansoorian received his Master's degree in Environmental Health Engineering from the Kerman University of Medical Science, Iran, in 2010. In 2011, he joined the Department of Environmental Health Engineering, University of Kerman, as a Lecturer, and became a PhD student in 2014. His current research interests include water and wastewater treatment and solid waste management and is the author of more than 50 scientific publications.

Mostafa Alizadeh is a graduate student in Environmental Engineering at Zahedan University of Medical Sciences. He is the author of one book, more than 10 scientific publications. His field of activities is the treatment of water and wastewater.

Abdolvahab Baghbanian has academic qualifications at Doctoral (PhD), Master, Bachelor and Graduate Levels with a focus on healthcare policy, health economics, social sciences, occupational health and safety, and hospital administration. Dr. Baghbanian has previously been appointed as an Australian registered migration agent and Director at GeemGate Pty. Ltd. He has served on many occasions as an academic, advisor and consultant to several regional, national and international governmental institutions. He has been commissioned to conduct many national and international training courses, research projects and workshops on the administrative, financial and policy aspects of health care and social sciences, including immigration and emigration. 